\title{
Myotonic Disorder
}

National Cancer Institute

\section{Source}

National Cancer Institute. Myotonic Disorder. NCI Thesaurus. Code C84913.

An inherited or acquired, localized or generalized disorder affecting the muscles. It may be associated with abnormalities in the chloride or sodium channels of the muscles. It is characterized by delayed muscle relaxation following stimulation or contraction. Representative examples include myotonia congenita and myotonic dystrophy. 